REVES - Revista Relações Sociais, Vol. 05 N. 01 (2022)

https://periodicos.ufv.br/reves

eISSN: 2595-4490

REVES-ReVista Relacōes Sociais (eISSN 2595-4490)

\title{
Educação Ambiental e Educação Física: Articulação Exitosa em uma Escola Rural de Uruguaiana-RS
}

\section{Environmental Education and Physical Education: Successful Articulation in a Rural School in Uruguaiana-RS}

\author{
Maria Elisabeth Valls de Moraes \\ ORCID: https://orcid.org/0000-0002-0598-5342 \\ Secretaria Municipal de Uruguaiana, Brasil \\ E-mail: melisabethmoraes@gmail.com \\ Fernando Icaro Jorge Cunha \\ ORCID: https://orcid.org/0000-0002-0064-4039 \\ Universidade Federal do Pampa, Brasil \\ E-mail: icaro729@gmail.com
}

Article Info:

Article history: Received 2021-10-22

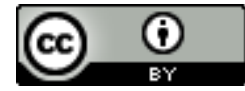

Accepted 2021-11-28

Available online 2021-11-28

doi: 10.18540/revesvl5iss1pp13462-01-09e

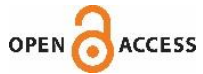

Resumo. Este é um projeto de pesquisa de Educação Ambiental (EA) baseado na Agenda 2030 para o Desenvolvimento Sustentável da Organização das Nações Unidas (ONU) em seu objetivo 12 - consumo e produção sustentáveis desenvolvido parcialmente em 2020 em virtude da pandemia de Covid-19. Realizou-se na Escola Municipal de Educação Básica (EMEB) Dr. Crespo de Oliveira no município de Uruguaiana, participante do Programa de Educação Ambiental da Rede Municipal de Ensino (PEARME), projeto de extensão da Universidade Federal do Pampa (UNIPAMPA) - campus Uruguaiana. EA é um tema transversal necessário a ser debatido nesta escola localizada na zona rural que vivencia os efeitos positivos e negativos da produção agrícola, seus descartes e não conta com a coleta seletiva do município. O projeto foi planejado para oito aulas de Educação Física (EF) e articulado com a EA. Os objetivos são: propiciar o entendimento dos alunos dos anos finais do correto descarte dos produtos orgânicos e secos nas lixeiras adequadas e evidenciarem o cuidado com a limpeza, organização e estética da escola. Este cuidado está relacionado com educar, com agir pensando nas relações entre os seres vivos e os ambientes onde vivem. Funcionários/as, professores/as e equipe diretiva participaram da execução do estudo. Os resultados foram parcialmente atingidos em um menor número de aulas, mas a pesquisa evidenciou a adesão dos alunos ao trabalho em grupo e o cuidado com a escola. Ficou evidente a relação entre EF e EA na construção do conhecimento de maneira integrada.

Palavras-chave: Educação ambiental. Descarte. Transversalidade. Protagonismo 
Abstract. This is an Environmental Education (EA) research project based on the 2030 Agenda for Sustainable Development of the United Nations (UN) in its goal 12 - sustainable consumption and production partially developed in 2020 due to the Covid-19 pandemic. It took place at Dr. Crespo de Oliveira Municipal School of Basic Education (EMEB) in the municipality of Uruguaiana, participant of the Environmental Education Program of the Municipal Education Network (PEARME), extension project of the Federal University of Pampa (UNIPAMPA) - campus Uruguayan. EE is a necessary crosscutting theme to be debated in this school located in the rural area, which experiences the positive and negative effects of agricultural production, its disposal and does not have selective collection in the municipality. The project was planned for eight Physical Education (PE) classes and articulated with the EA. The objectives are: to provide students in the final years with an understanding of the correct disposal of organic and dry products in the proper bins and to demonstrate care with the school's cleanliness, organization and aesthetics. This care is related to educating, with acting thinking about the relationships between living beings and the environments in which they live. Employees, professors and management team participated in the execution of the study. The results were partially achieved in a smaller number of classes, but the research showed the students' adherence to group work and care for the school. The relationship between PE and EE in the construction of knowledge in an integrated manner was evident.

Keywords: Environmental education. Discard. Transversality. Protagonism.

\section{Introdução}

Este trabalho faz parte do Programa de Educação Ambiental da Rede Municipal de Ensino (PEARME), projeto de extensão da Universidade Federal do Pampa (UNIPAMPA) - campus Uruguaiana com o apoio da Secretaria Municipal de Educação (SEMED). A proposta deste programa advém de "discussões e reflexões sobre as questões ambientais, globais e regionais" (1 EEAFO, 2021) em diversos cursos. $O$ PEARME tem o intuito de ampliar o conhecimento e a prática pedagógica de EA nas escolas da rede municipal de ensino de Uruguaiana e acontece mensalmente em reuniões de Formação Continuada na SEMED com representantes de professores/as destas escolas. Um recorte deste trabalho foi apresentado na primeira edição do encontro de Educação Ambiental da Fronteira Oeste.

Foi sorteado em reunião deste programa em 2020, o Objetivo de Desenvolvimento Sustentável (ODS) de número doze (12) para a Escola Municipal de Educação Básica (EMEB) Dr. Crespo de Oliveira na qual trabalho. Este, inscreve-se nos 17 objetivos para transformar o mundo, proposto em 2015 pelos 193 representantes dos Estados-membros da Organização das Nações Unidas (ONU). Está baseado na Agenda 2030 para o Desenvolvimento Sustentável, compromisso para erradicar a pobreza extrema a nível global, a partir da mescla das dimensões sociais, ambientais e econômicas (Plataforma Agenda 2030, 2021). De acordo com esta agenda foi realizado este projeto de pesquisa em Educação Ambiental com participações diferenciadas de todas as turmas da escola desde a Educação Infantil aos Anos Finais, com aprofundamento nos últimos anos do Ensino Fundamental. 
O ODS 12 trata do Consumo e Produção Sustentáveis, porém é um objetivo muito complexo para um trabalho em grupo somente no componente curricular de Educação Física, com dois períodos semanais. Acredita-se na possibilidade de realizar um estudo com alunos/as coletando e separando os diversos descartes na escola. Contribuindo para a limpeza e cuidado da sala de aula, quadra esportiva, pátios e demais dependências da escola, nos períodos de Educação Física escolar e enlaçando-se a EA. Dessa maneira, proporcionando por meio deste estudo um processo pedagógico lúdico evidenciado no protagonismo, no trabalho coletivo e na reflexão acerca das relações dos seres vivos com o Planeta.

[...] Isto implica em uma desconstrução do pensamento disciplinador, fragmentador e simplificador para outro espaço pedagógico em que o mundo seja potência e possibilidade de construção do conhecimento, pela relação do ser humano com a natureza, a partir do seu meio e da sua produção cultural. (DOMINGUES et al., 2011, p. 566).

O valor do cuidado nesta pesquisa remete ao entendimento das Diretrizes Curriculares Nacionais da Educação Básica explicando que "Educar exige cuidado; cuidar é educar[...] no sentido de desenvolver o aprendizado de pensar e agir, cuidar de si, do outro, da escola, da natureza, da água, do Planeta (2013)." Para ocorrer um projeto com alunos necessita-se da adesão destes/as e de um trabalho do grupo em prol da tarefa escolhida, além de outras condições ofertadas pela escola, seus/as funcionários/as, professores/as e equipe diretiva.

Contou-se com o apoio dos/as demais professores para eventuais atividades em conjunto. Este projeto não foi totalmente finalizado como havia sido planejado em virtude da pandemia de Covid-19 ter se instalado no Brasil em março de 2020 fechando as portas das escolas para aulas e projetos presenciais durante a maior parte do referido ano.

A separação dos descartes visa contribuir para o entendimento de que existem materiais recicláveis e não recicláveis, aos quais atribuímos a denominação de descarte seco, além do descarte orgânico. Existem alguns descartes que não são recicláveis e como se desfazem na natureza? Onde se depositam os diversos descartes da cidade de Uruguaiana?

Reconhecer que os desequilíbrios ambientais estão relacionados intrinsecamente às condutas humanas inadequadas favorece a construção do pensamento crítico acerca das causas e dos efeitos entre ser humano e meio ambiente. A educação ambiental é ferramenta essencial nesse processo, pois possibilita uma visão holística sobre o sistema, ao mesmo tempo que correlaciona diferentes temas visando a uma maior compreensão. Existem três fatores extremamente delicados que podem ser pautados de forma conjunta para maior entendimento dos estudantes: o destino de resíduos, o desperdício de água e 0 de alimentos (ALMEIDA; JUNIOR; NUNES; LIZ, 2019. p. 484).

Compreendemos que EA é um conhecimento transversal a todas as disciplinas e extremamente necessário atualmente, e em especial, em uma escola rural onde seus/as alunos/as convivem diariamente em suas moradias com plantações de arroz e descartes dos envoltórios de produtos químicos, além do descarte dos produtos orgânicos e secos da escola conjuntamente, sem uma coleta seletiva na vila onde está localizada a escola, entre outros. 
Sabe-se da relevância da Educação Ambiental, portanto, a consciência ecológica deve ser adquirida desde cedo. Assim, a Educação Física Escolar, integrada a outras disciplinas, deve promover atividades que estimulem a reflexão sobre os benefícios que a preservação do meio ambiente pode oferecer aos próprios alunos (RIOS; SOUSA FILHO, RIBEIRO, 2018, p. 54).

O descarte é algo que se depreciou, que se desvalorizou de acordo com Leonard (2010) e esclarece que lixo são coisas que jogamos em uma lixeira e que misturadas são recursos que destruímos; separados, são recursos aproveitáveis (LEONARD, 2010). De acordo com Amorim (2010), "lixo é tudo que nós descartamos por não querermos mais, ou por não percebermos uma utilidade imediata. O lixo vira resíduo quando é reaproveitado."

Neste trabalho frisou-se a separação dos descartes em secos e orgânicos para iniciar uma conscientização sobre a colocação de descartes em lixeiras apropriadas, além do cuidado com os ambientes da escola em que estudam cotidianamente. Dessa maneira justifica-se a importância desta pesquisa e seus objetivos. A metodologia esclarece como pretendemos realizar e organizar este estudo. Nos resultados analisamos o que foi feito e o que se conseguiu finalizar em virtude de a pandemia ter abreviado o tempo das aulas presenciais e constatações dos alunos/as. Nas conclusões, agregamos outras percepções do coletivo docente e discente. O principal objetivo desta pesquisa é o entendimento pelos/as alunos/as dos anos finais do correto descarte dos produtos orgânicos e secos nas lixeiras correspondentes. O segundo: organizar em grupo a tarefa ambiental escolhida na turma. Terceiro: evidenciarem o cuidado com a limpeza, organização e estética da escola.

\section{Procedimentos Metodológicos}

Este estudo caracteriza-se como uma pesquisa de campo, em delineamento qualitativo e exploratório. "Na pesquisa de campo, o objeto/fonte é abordado em seu meio ambiente próprio. A coleta dos dados é feita nas condições naturais em que os fenômenos ocorrem, sendo assim diretamente observados, sem intervenção e manuseio por parte do pesquisador" (SEVERINO, 2013, p. 107).

Acerca da pesquisa qualitativa, nos amparamos em Martins (2004), quando afirma que:

A pesquisa qualitativa é definida como aquela que privilegia a análise de microprocessos, através do estudo das ações sociais individuais e grupais, realizando um exame intensivo dos dados, e caracterizada pela heterodoxia no momento da análise (MARTINS, 2004, p. 289).

Esta pesquisa foi apresentada à equipe diretiva da escola para realizar-se nos momentos das aulas de Educação Física no início de 2020. Professores e professoras foram comunicados do estudo e foi solicitado seu apoio. Foi realizada reunião com funcionários/as para ouvi-los/as e planejar atividades. Foi perguntado o que entendiam por ambiente e no entender deles/as o que poderia melhorar nos ambientes da escola. As turmas de 6 a 9o anos organizaram-se em grupos, e caminharam pelas dependências da escola, pátios (interno e externo) e quadra esportiva. Observaram 
todas as dependências da escola junto com a professora, registraram no caderno ou em fotos, problemas que poderiam resolver ou minorar. Verificaram também, se a escola, no geral, praticava a separação de descartes em cada lixeira correspondente. Ao final da primeira e segunda aulas, as turmas participaram de um jogo ambiental chamado Cidade Limpa constando de coleta seletiva em uma cidade (Figura 1).

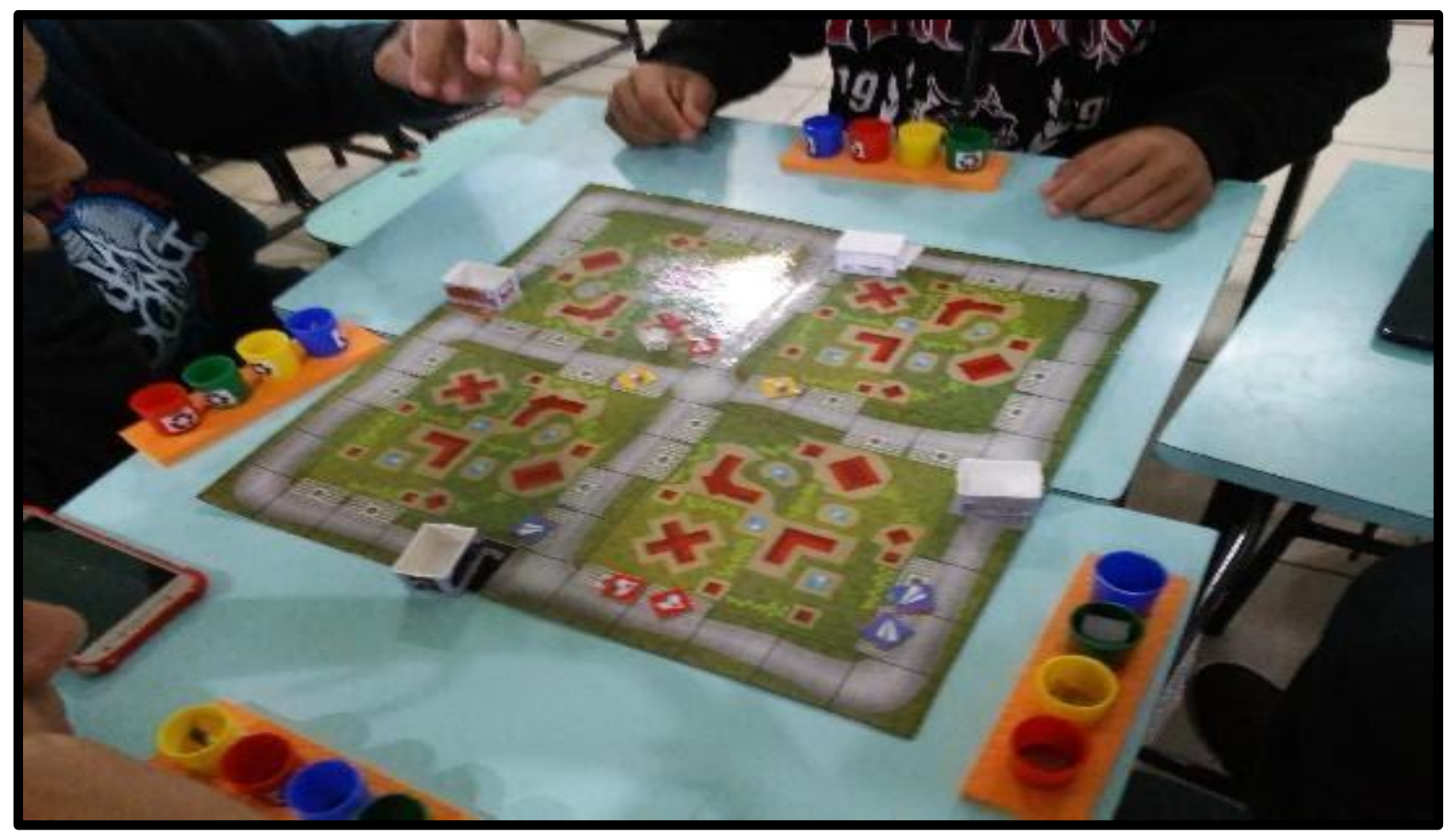

Figura 1 - Estudantes jogando "Cidade Limpa"

Fonte: Os autores (2021).

Após, em cada turma, os grupos escolheram o que gostariam de fazer atrelados ao que haviam verificado na escola e ao tema do projeto de Educação Ambiental: separação de descarte orgânico e seco - limpeza e cuidados com os ambientes da escola. No desenrolar das aulas os grupos iam se organizando, pensando e solicitando material necessário, caso tivessem em sua moradia, poderiam trazer para serem usados. Foi pensado utilizarmos o final do mês de fevereiro e o mês de março, em um total de 8 aulas para a realização do projeto. Entendemos que os alunos da Educação Infantil (EI), duas turmas de 12 crianças, aproximadamente e dos Anos Iniciais (AI), 5 turmas, de aproximadamente, 15 crianças em cada turma, teriam condições de participar contribuindo com o estudo.

As tarefas escolhidas constaram de explicações aos alunos de educação infantil e anos iniciais sobre o que são descartes orgânicos e secos e a colocação correta destes descartes nas lixeiras correspondentes, como utilizar adequadamente os banheiros masculinos e femininos, catarem descartes nos ambientes da escola e separarem em seco e orgânico, agrupar grama cortada, juntá-la e após colocá-la em cima da composteira organizada por outro grupo. Colocação de mais lixeiras no pátio interno e externo (Figura 2). Redigir um bilhete para motoristas que frequentam a escola solicitando cuidado com a velocidade na estrada para evitarem a morte de animaizinhos. Limpeza da quadra esportiva e suas imediações, realização de uma composteira. Limpeza, colocação de terra e rega de água em plantas da escola. 


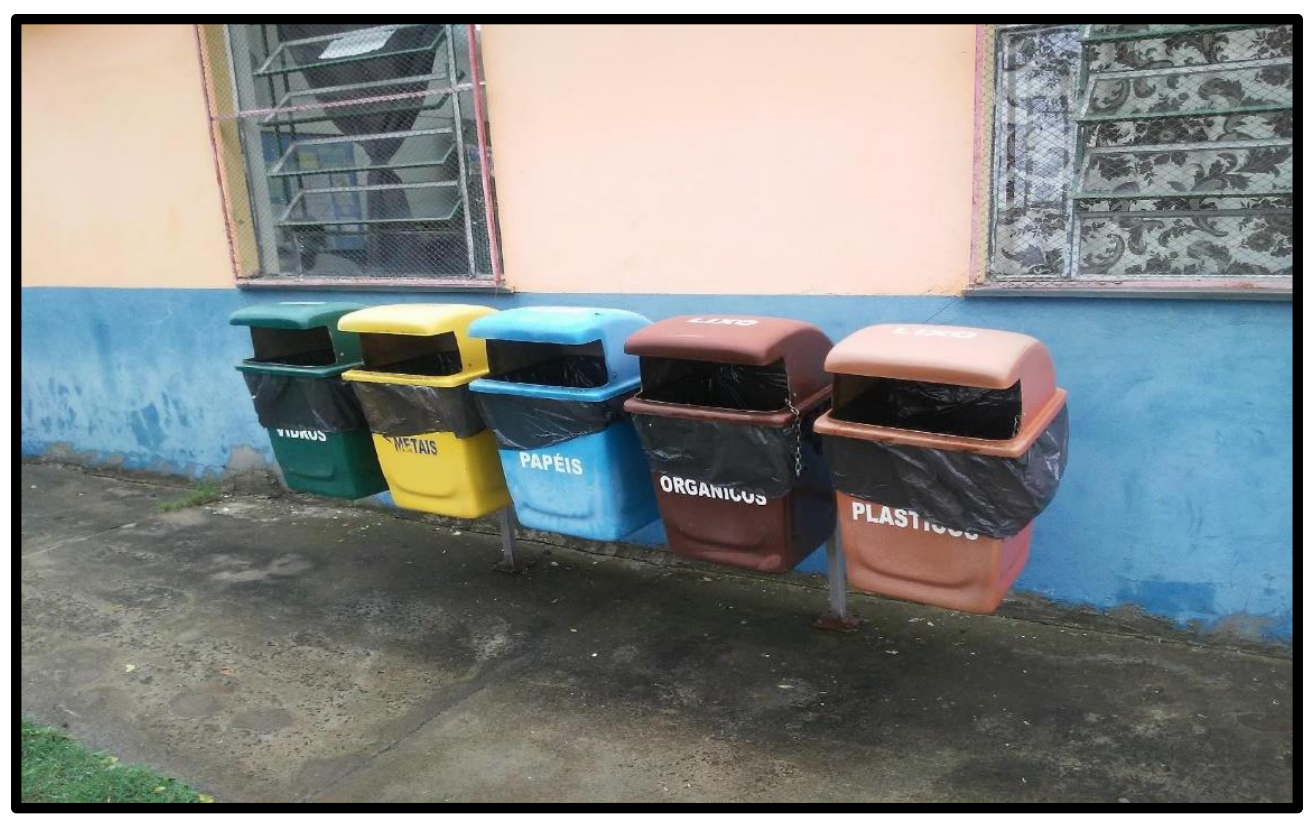

Figura 2 - Lixeiras seletivas da escola

Fonte: Os autores (2021).

Após concluídas as tarefas, far-se-ia uma reunião em cada turma dos Anos Finais para conversar sobre as tarefas realizadas, recorrer-se-ia a escola novamente tirando fotos para registro das diferenças observadas. Haveria uma roda de conversa em cada turma sobre novos entendimentos e possíveis modificações nas atitudes de cada um/a em relação a este trabalho. Por último, pedir-se-ia aos/às demais professores/as e funcionários/as uma pequena avaliação, individual ou dos grupos sobre a realização do projeto na escola que posteriormente seria comunicado às turmas.

\section{Resultados e Discussão}

Algumas tarefas foram concluídas, outras não. Principalmente as que se utilizavam de textos explicativos às crianças de El e Al e bilhetes aos/às motoristas frequentadores/as da escola, não foram totalmente finalizadas. As tarefas estéticas, de limpeza e organização de composteira foram totalmente concluídas. A colocação de mais lixeiras de descarte seco e orgânico no pátio interno não foi completada e constatou-se que os alunos da escola não colocavam seus descartes nas lixeiras correspondentes. Não foi apropriado totalmente pelos alunos que a escola junta os descartes secos aos orgânicos para o caminhão do lixo levar tudo junto. No jogo de tabuleiro foi notado que não constava a lixeira de orgânicos. Apreciaram o jogo e deram- se conta que havia uma estratégia de percurso dos caminhões nas quadras urbanas para o recolhimento das lixeiras. Não houve evolução em outras estratégias do jogo em vista do tempo exíguo. As avaliações e a roda de conversa não foram realizadas, mas os alunos do $6 \div$ a 9 anos realizaram, individualmente, uma avaliação de modo remoto sobre o projeto e de maneira positiva externaram seus entendimentos e percepções.

Os resultados foram satisfatórios mesmo com o pouco tempo de realização. As turmas dos Anos Finais realizaram as atividades escolhidas e as turmas dos Anos 
Iniciais e Educação Infantil participaram como audiência contribuindo com suas opiniões. Houve uma interação entre professora de EF e funcionários e ficou demonstrado um entendimento do trabalho realizado embora não concluído. A professora também percebeu a relação amigável entre alunos e funcionários, e na observação e convivência com estes grupos, sentiu-se aprendiz e educadora como explica Paulo Freire: "quem ensina aprende ao ensinar, e quem aprende ensina ao aprender” (FREIRE, 1996, p. 25).

A maioria dos alunos demonstrou ampla adesão e entendimento da proposta. No $6^{\circ}$ ano todos os catorze alunos realizaram a tarefa escolhida nos grupos. No $7^{\circ}$ ano com dezenove alunos, dezessete participaram do projeto, a dupla faltante não foi frequente à escola neste período. No $8^{\circ}$ ano, os treze alunos participaram do projeto e no $9^{\circ}$ ano dos dezoito, uma só pessoa foi infrequente.

Houve uma evolução nas relações sociais, no cuidado com a escola e na compreensão da relação entre as atitudes dos seres humanos e a preservação e continuidade da vida no Planeta demonstradas nestas transcrições: "... você precisa pensar antes de jogar papel". Esta estudante declara isso, após seu grupo ter separado os descartes encontrados pelo chão da escola, organizando-os nas lixeiras adequadas, incentivando a conscientização; outro diz que "aprendi a utilidade da composteira" entendendo por que é útil e que pode fazer em sua casa, disseminando esta prática ao reutilizar material orgânico.

"Eu aprendi que devemos cuidar do nosso planeta e do ambiente que a gente vive, e se a gente fizer isso irá preservar o planeta e a nossa saúde." Compreende a relação entre o que faz nos ambientes que vive, a saúde do Planeta e a sua saúde. "Aprendi que o ambiente tem que "estar" em nós para podermos viver, e vi (infelizmente) o quão maltratado ele é. [...], mas também não vi apenas coisas ruins. Vi e posso afirmar que eu pude fazer parte do "movimento" ao meio ambiente[...] eu pude ajudar [...] de algumas formas." Sente-se parte do ambiente e não um espectador da natureza, importante "insight"! Outra aluna diz que "Foi incrível eu aprendi a trabalhar em grupo, também a cuidar da escola e a importância de separar o lixo." Entrelaça importantes aprendizados, o humano vive em grupo, ao estudar sobre a vida precisa manter seus ambientes livres de descartes, colocando-os nos lugares adequados. É possível verificar o êxito deste trabalho através da visualização das figuras 3 e 4 .

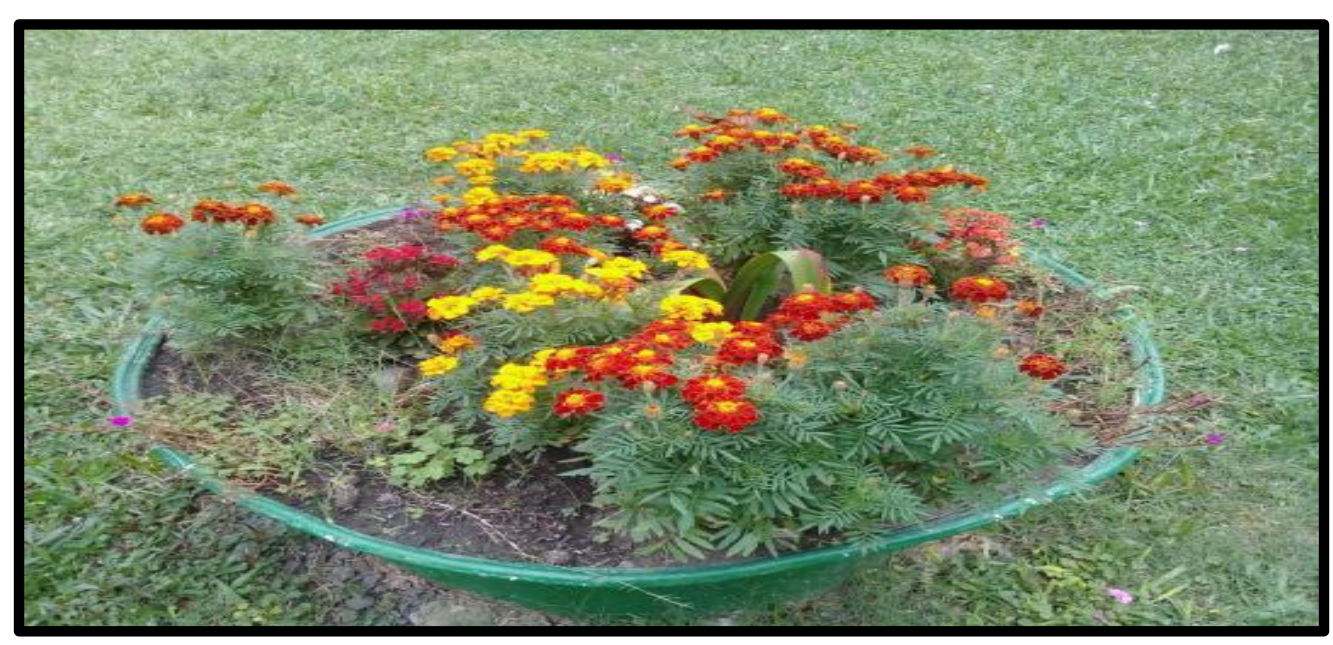

Figura 3 - Plantas organizadas pelos estudantes

Fonte: Os autores (2021). 


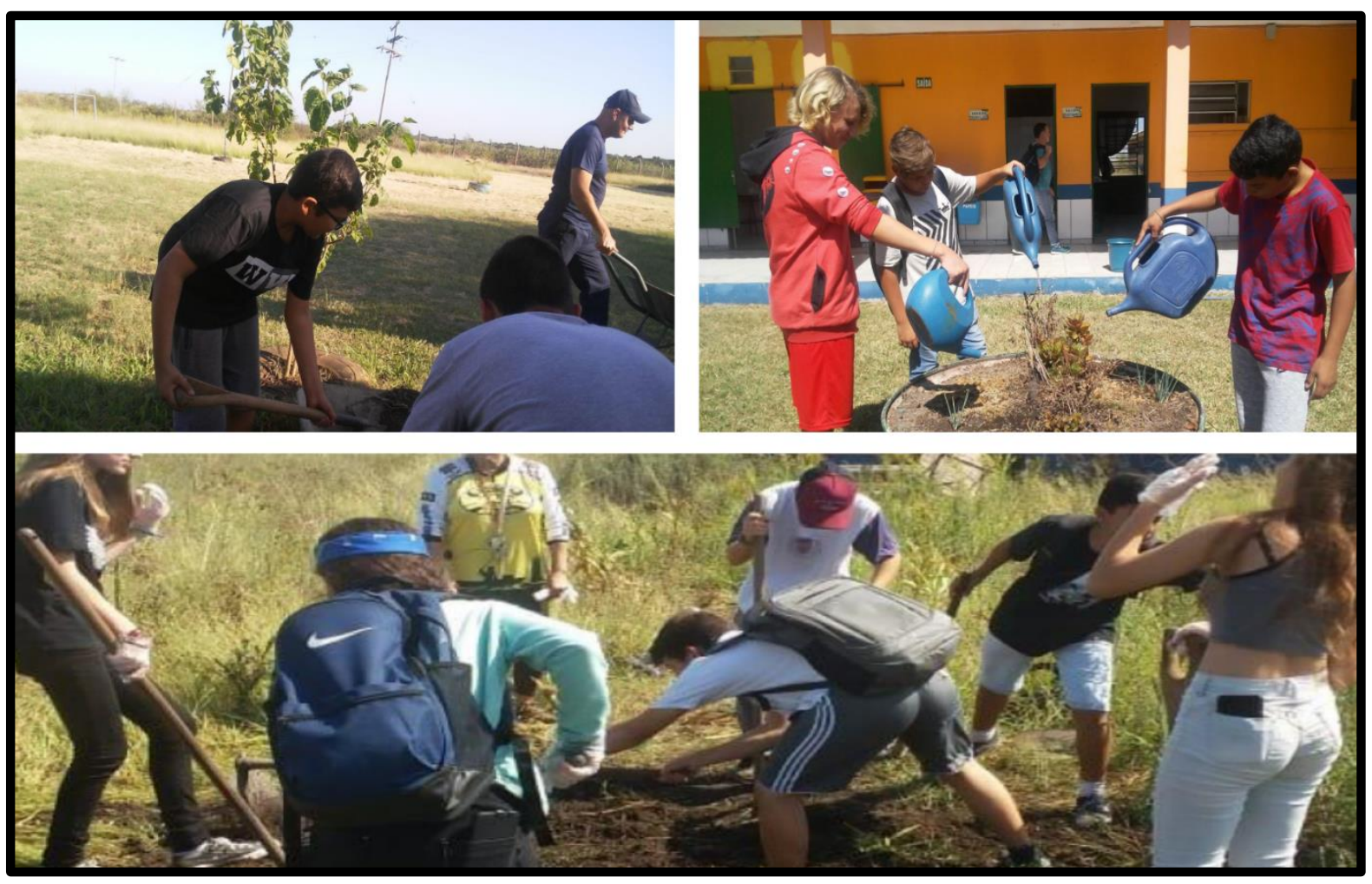

Figura 4 - Limpeza, rega das plantas e criação da composteira Fonte: Os autores (2021).

O cuidado com a escola foi enormemente demonstrado com a atitude de um grupo de alunos/as. Solicitaram ao professor de Técnicas Agrícolas para comprar mudinhas de flores na cidade para colocarem em alguns lugares escolhidos por eles/as na escola e contribuíram financeiramente para este fim.

\section{Considerações Finais}

Neste estudo ocorreu o entendimento do correto descarte, houve a organização necessária para realização de tarefas em grupo e ficou demonstrado o cuidado com os ambientes, refletindo-se na limpeza e estética da escola. A temática do projeto foi facilmente entendida e executada pela articulação da Educação Ambiental com a Educação Física.

Outros valores alcançados, podem ser citados, tais como: participação, trabalho em equipe e engajamento. Para além, o rendimento foi meramente satisfatório, asseverando a importância de fomentar os conhecimentos da Educação Ambiental durante as aulas de Educação Física.

Os resultados apontam que a adesão ampla dos/as alunos/as aos trabalhos em grupos demonstrou a eficácia do protagonismo, a satisfação de realizar com colegas o que haviam pensado em fazer. A disponibilidade dos/as funcionários/as, dos/as alunos/as das demais etapas e a compreensão dos/as professores/as evidenciou a parceria ampla que acontece na escola tornando eficiente e prazerosa a vida escolar.

Durante a apresentação no Encontro de Educação Ambiental da Fronteira Oeste, o trabalho atingiu êxito pela riqueza do protagonismo dos educandos, contagiando os participantes da Roda de Compartilhamento. Na avaliação final dos 
estudantes, os mesmos relataram a importância do projeto e a satisfação em participar.

\section{Agradecimentos}

Ao Encontro de Educação Ambiental da Fronteira Oeste;

À Universidade Federal do Pampa;

À Secretaria de Educação de Uruguaiana-RS;

À Revista Relações Sociais.

\section{Referências}

ALMEIDA, Nayara Cristina Caldas; JUNIOR, Cezário Ferreira dos Santos; NUNES, Aline; LIZ, Mariane Souza Melo de. Educação ambiental: a conscientização sobre o destino de resíduos sólidos, o desperdício de água e o de alimentos no município de Cametá/PA. Revista Brasileira de Estudos Pedagógicos, v. 100, n. 255, 2019. Doi: https://doi.org/10.24109/2176-6681.rbep.100i255.4007.

AMORIM, Aline Pinto, et al. Lixão Municipal: abordagem de uma problemática ambiental na cidade do Rio Grande-RS. Revista Ambiente e Educação, v. 15, n. 1, p. 162, 2010.

BRASIL. Ministério da Educação. Secretaria de Educação Básica. Secretaria de Educação Continuada, Alfabetização, Diversidade e Inclusão. Diretrizes Curriculares Nacionais Gerais da Educação Básica. Diretoria de Currículos e Educação Integral. Brasília: MEC, SEB, DICEI, 2013.

BRASIL. Secretaria de Educação Fundamental. Parâmetros Curriculares Nacionais: terceiro e quarto ciclos: apresentação dos temas transversais. Secretaria de Educação Fundamental. Brasília: MEC/SEF, 1998.

DOMINGUES, Soraya Corrêa; KUNZ, Elenor; ARAUJO, Lísia Costa Gonçalves de. Educação ambiental e educação física: possibilidades para a formação de professores. Rev. Bras. Ciênc. Esporte, Porto Alegre, v. 33, n. 3, p. 559-571, 2011. Disponível em https://doi.org/10.1590/50101-32892011000300003 Acesso em 05/04/21.

I ENCONTRO DE EDUCAÇÃO AMBIENTAL DA FRONTEIRA OESTE, Palavras Iniciais, 2021. Disponível em: https://www.even3.com.br/ieeafo2021/. Acesso em 22/03/21.

FREIRE, Paulo. Pedagogia da autonomia: saberes necessários à prática educativa. São Paulo: Paz e Terra, 1996. (Coleção Leitura), p.25.

LEONARD, Annie. A história das coisas: da natureza ao lixo, o que acontece com tudo que consumimos. RJ: Zahar, 2011, p.192.

Plataforma Agenda 2030. Disponível em: http://www.agenda2030.org.br> Acesso em 25/03/21.

RIOS, Shirlley Kelly Oliveira; SOUSA FILHO, Aldemir Ferreira de; RIBEIRO, Francisco Irapuan. Educação Física e Educação Ambiental e sua relação no contexto escolar.

Revista Brasileira de Educação Ambiental, v. 13, n. 12, 2018. Doi: https://doi.org/10.34024/revbea.2018.v13.2464.

MARTINS, Heloisa Helena Teixeira de Souza. Metodologia qualitativa de pesquisa. Educação e Pesquisa, São Paulo, v. 30, n. 2, p. 289-300, 2004. Doi: https://doi.org/10.1590/S1517-97022004000200007.

SEVERINO, Antônio Joaquim. Metodologia do Trabalho Científico. Cortez: 2013. 